\title{
Textile antenna systems for positioning and off-body communication
}

H. Rogier, S. Agneessens, F. Declercq, A.

Dierck, W. Joseph, M. Moeneclaey, L.

Vallozzi, P. Van Torre, J. Vanfleteren

Dept. of Information Technology

Ghent University 


\section{Outline}

- Wearable textile systems:

- Reliability concerns

- Energy-efficiency concerns

- MIMO techniques for off-body communication

- Reliability versus energy-efficiency

- Space-time coding versus beam forming

- Integrating energy harvesters on textile antennas

- Solar-cell PIFA antenna

- Robust wearable antennas for GPS/Galileo positioning

- Providing stable performance in adverse conditions

- On-body wearable repeater as relay for implants

- In-to-out body communication in an endoscopy application

- General conclusions 


\section{Textile antenna systems}

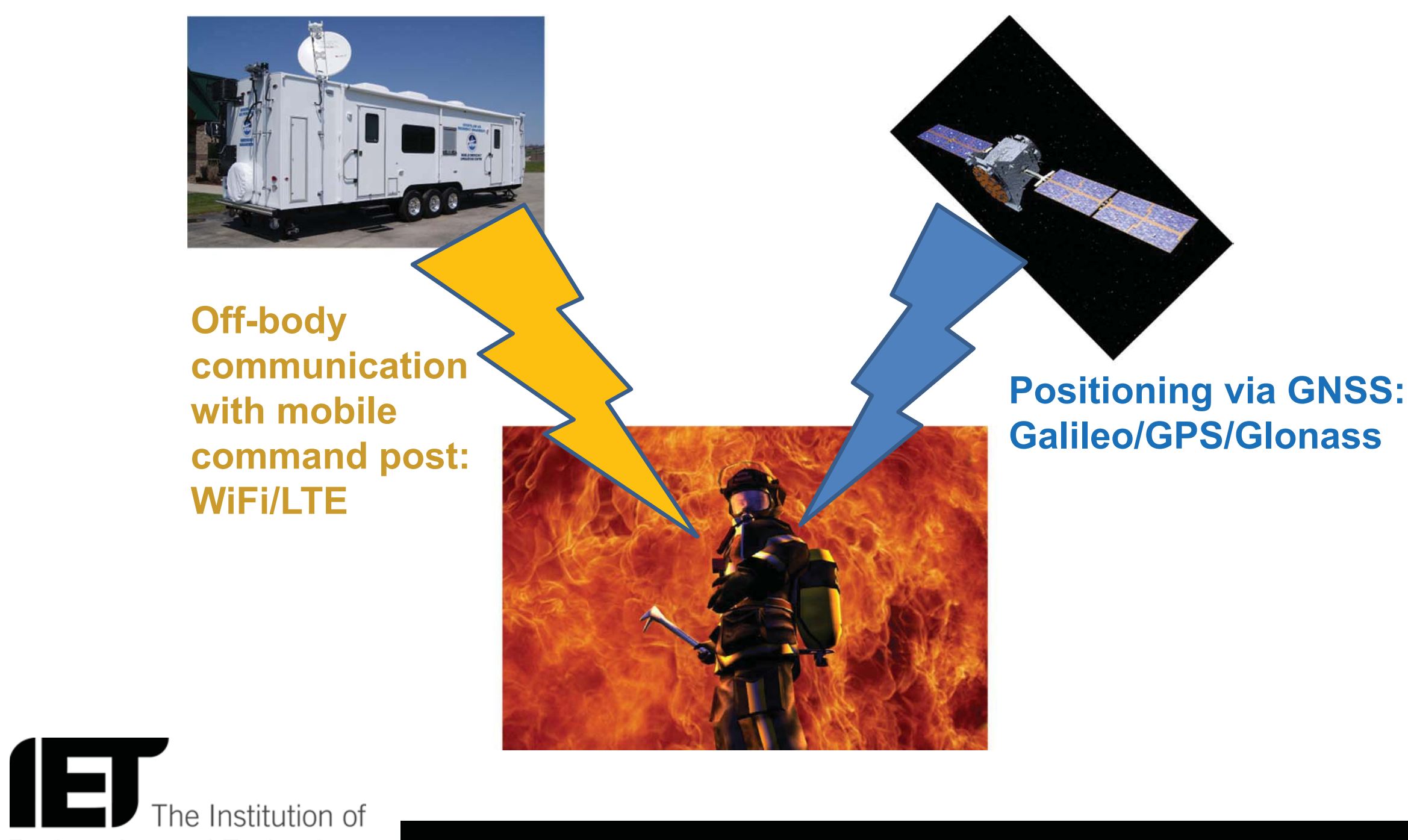




\section{A garment as antenna platform}

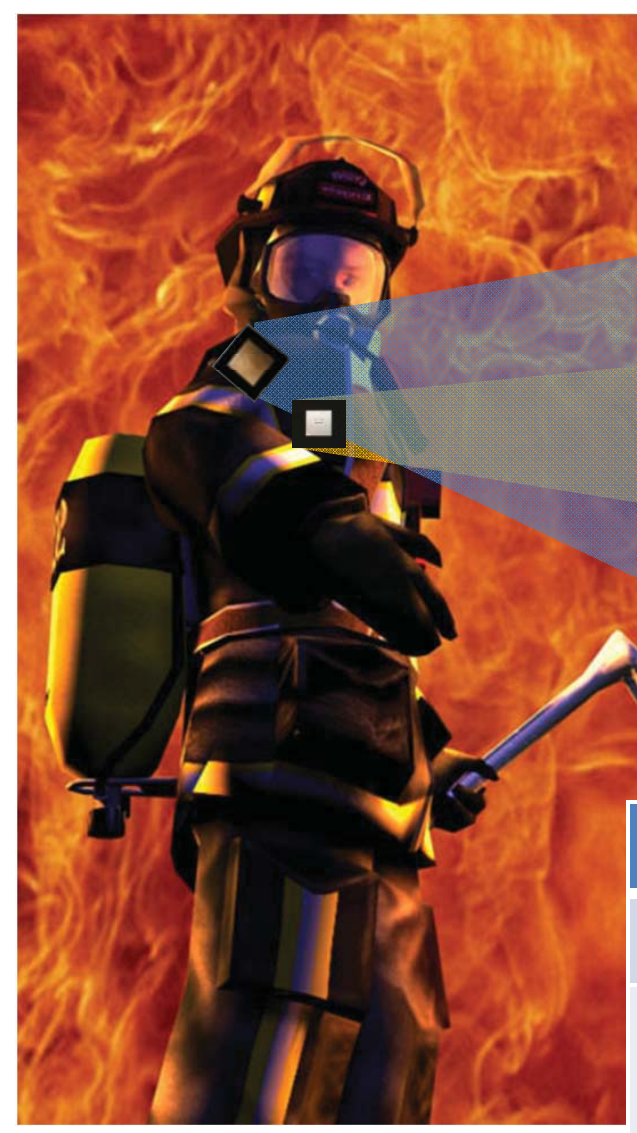

\section{Design requirement Issues \\ Robust wearable antennas}

Realisation of reliable off-body links

Reliable off-body communication link
Bending, wrinkling Body absorption Variable humidity

Fading

Body-shadowing

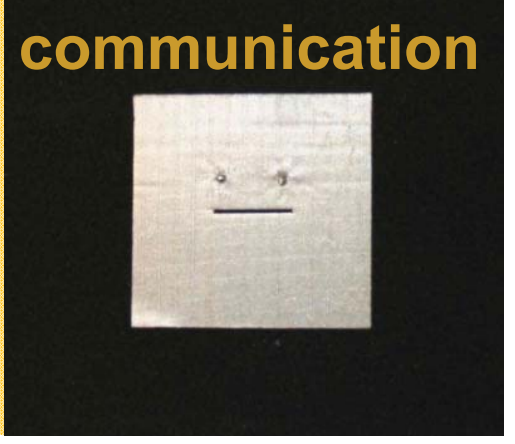

\section{Required properties}

Low-profile, light-weight Comfortable, breathable Stable high performance Quality independent of position and posture 


\section{Textile systems: reliability}

- First-generation textile system

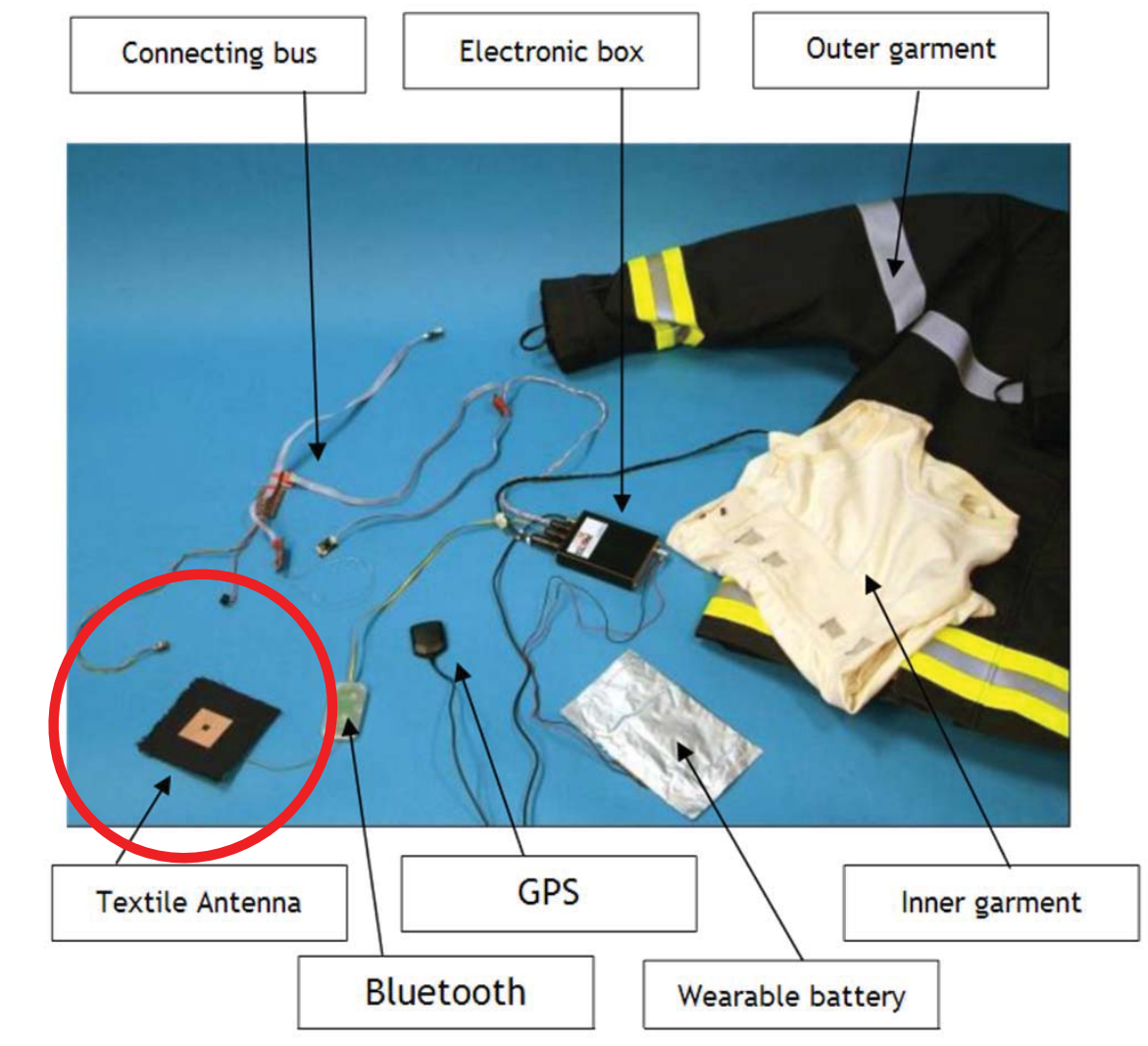

- Many modules connected by wires

- Expensive

- Many weak links electronics $\Leftrightarrow$ textiles

- Maintenance???

- washability?

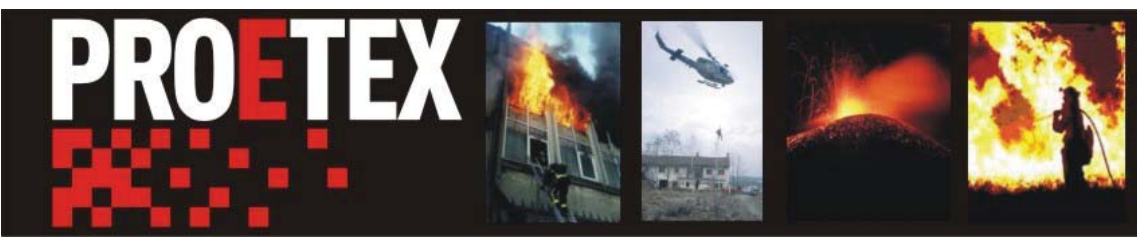

Project FP6-2004-IST-4-026987 


\section{Textile systems: energy supply}

- First-generation textile system

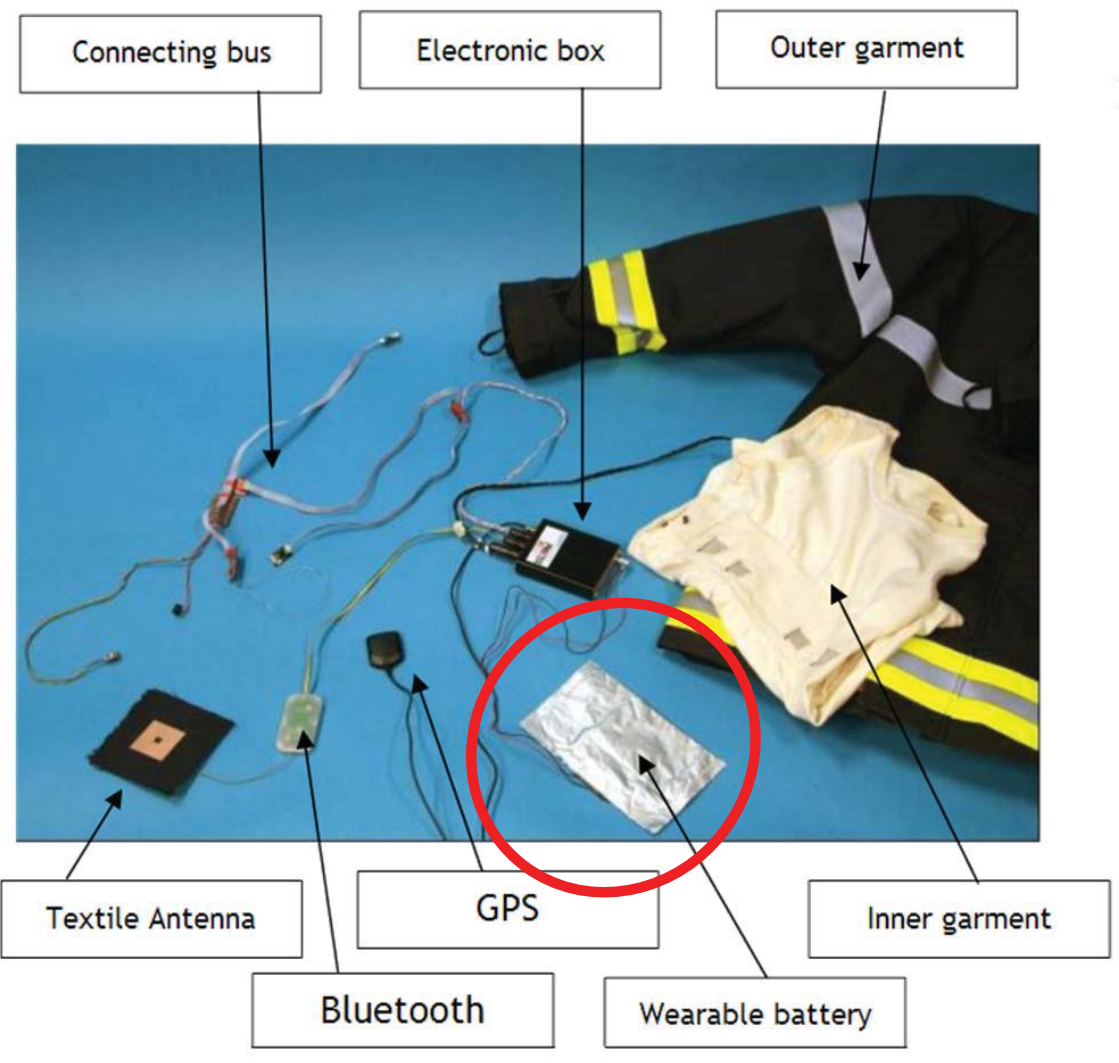

- Battery remains an issue

- Reliability

- Capacity

- Weight/Flexibility

- Frequent recharging

- Maintenance???

- washability?

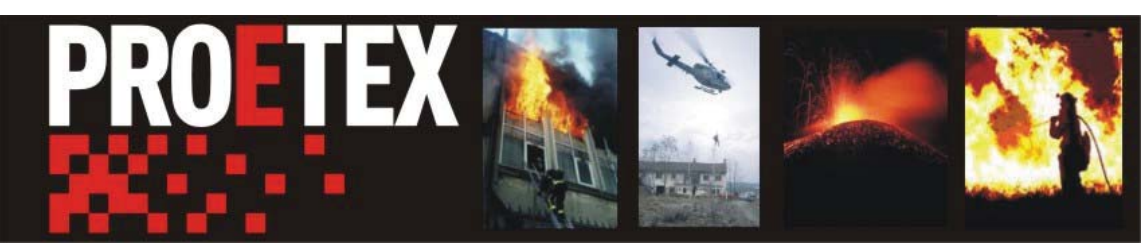

Project FP6-2004-IST-4-026987 


\section{Future textile systems}

- Reliable

- Ad-hoc network of textile antenna modules

- Compact, with integrated transceiver, energy supply/management, sensors, ...

- Wirelessly interconnected

- Washable by applying a TPU coating

- Energy-efficient + autonomous

- Designed for minimal energy consumption

- Energy-efficient MIMO techniques

- Integrated energy harvesters 


\section{Outline}

- Wearable textile systems

- Reliability concerns

- Energy-efficiency concerns

- MIMO techniques for off-body communication

- Reliability versus energy-efficiency

- Space-time coding versus beam forming

- Integrating energy harvesters on textile antennas

- Wearable Solar-cell PIFA antenna

- Robust wearable antennas for GPS/Galileo positioning

- Providing stable performance in adverse conditions

- On-body wearable repeater as relay for implants

- In-to-out body communication in an endoscopy application

- General conclusions 


\section{Static beamforming}

- Motivation: reliability vs. energy-efficiency

- Why static zero-elevation beam forming?

- Absence of channel information feedback

- Concentration of transmit power towards receiver on the same floor

- Low-cost implementation compared to space-time coding

- Beam forming versus space-time codes in equal propagation conditions

- Measurement in indoor environment 


\section{Experimental setup}
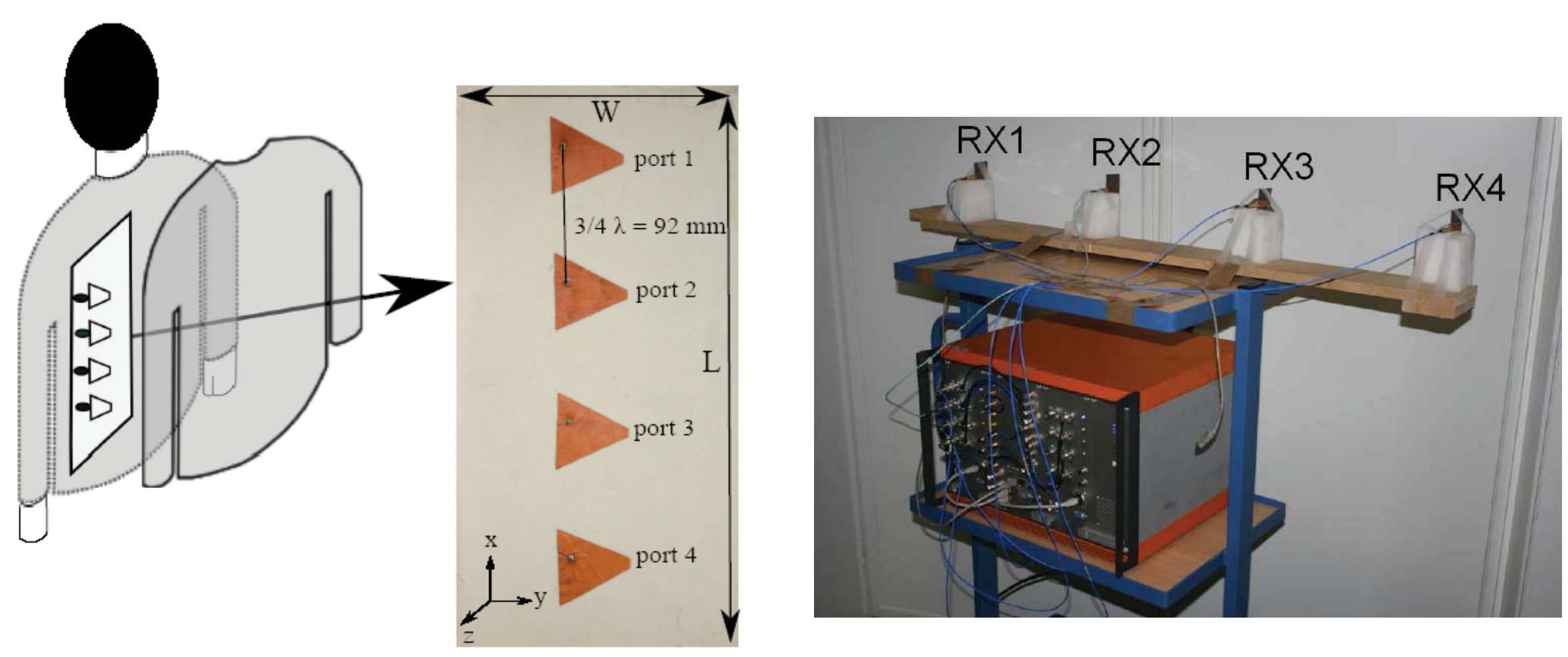

- Body-worn vertical textile array for space-time coding and beam forming

- Diversity receiver with maximal ratio combining

- Space-time coding and beam forming within each transmit frame 


\section{Propagation environment}

- Indoor measurement environment

- Line-of-sight (LoS) as well as non lineof-sight propagation (NLoS) paths

- Solid brick walls block direct signal paths

- Office equipment causes shadowing

- Moving people cause channel variability

- Beam forming in this environment

- Low-elevation signals provide higher average SNR at receiver

- Diversity needed at receiver to mitigate multipath signal variation

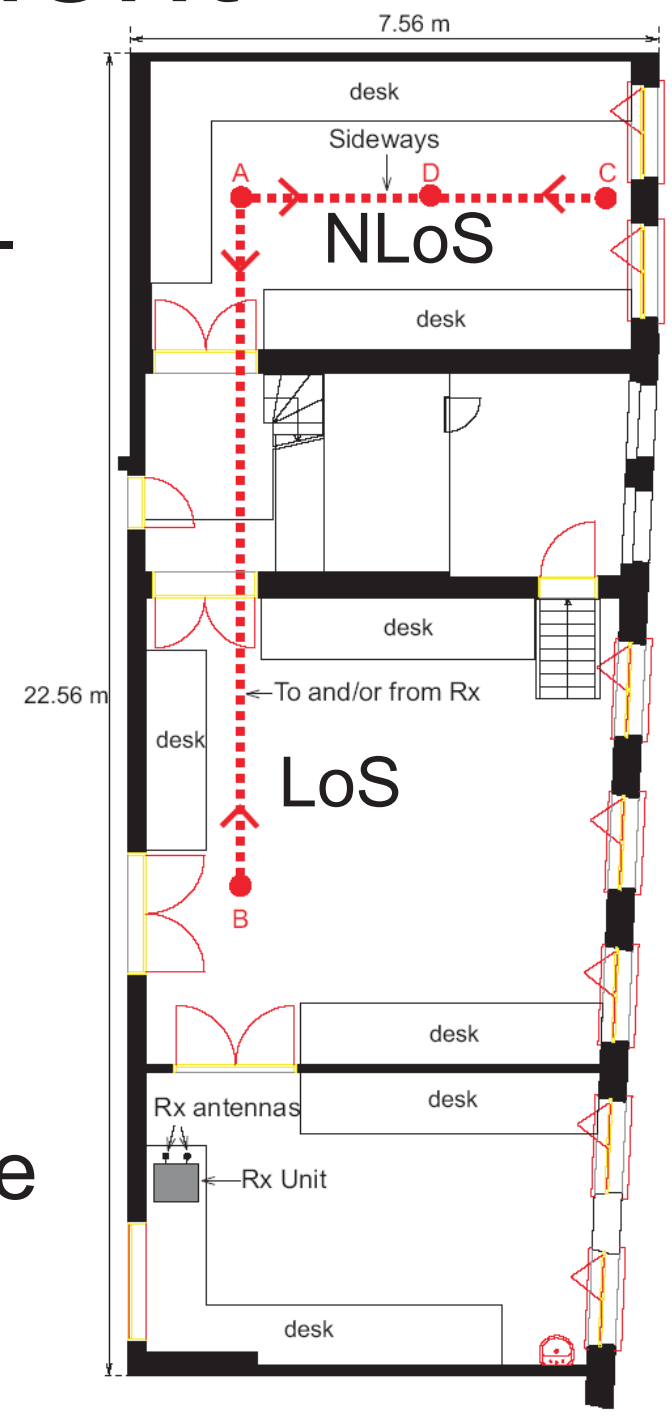




\section{LoS BER characteristics}

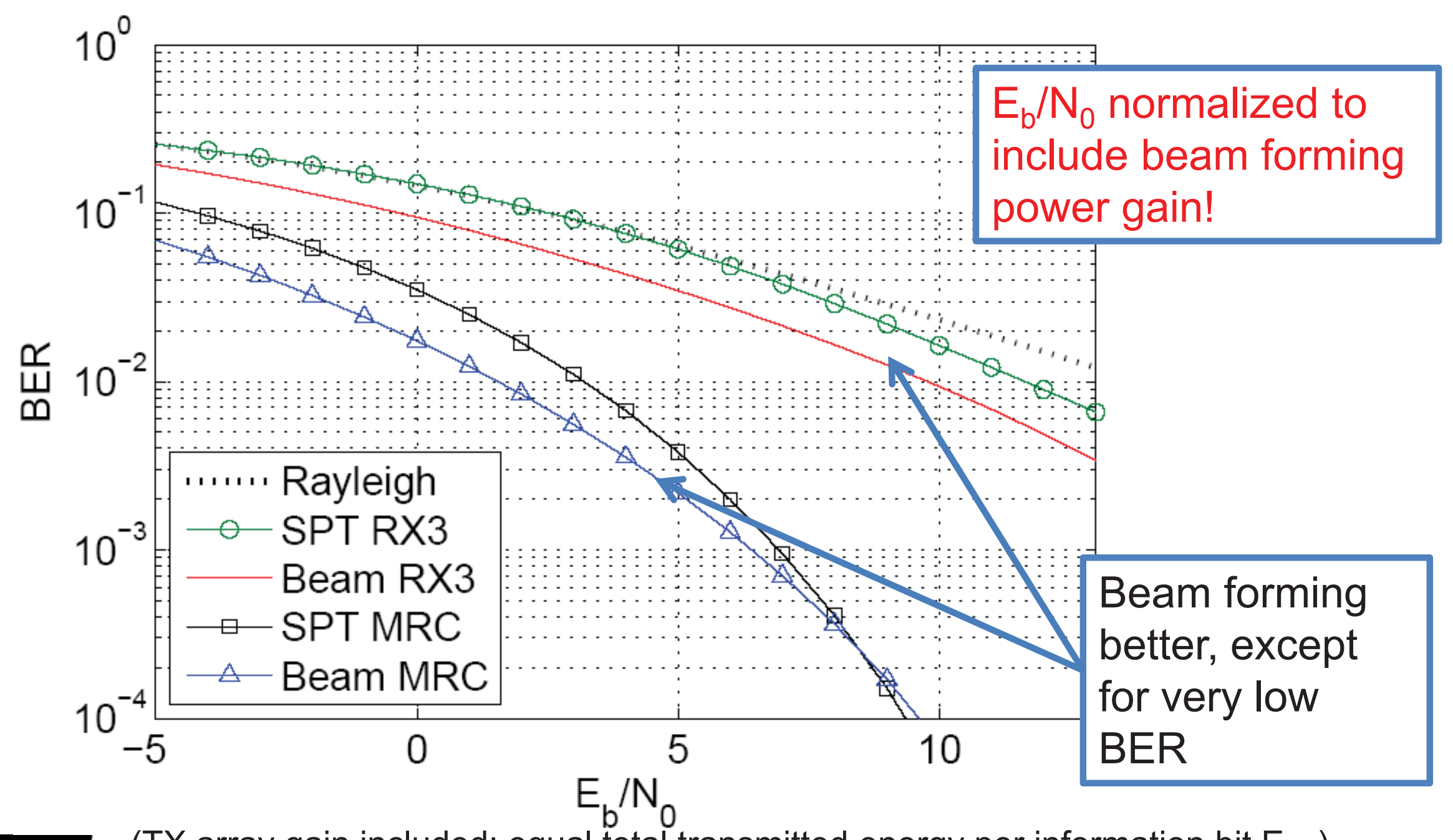

(TX array gain included: equal total transmitted energy per information bit $\mathrm{E}_{\mathrm{b}, \mathrm{tr}}$ ) SPT: space-time coding MRC: maximum-ratio combining 


\section{NLoS BER characteristics}

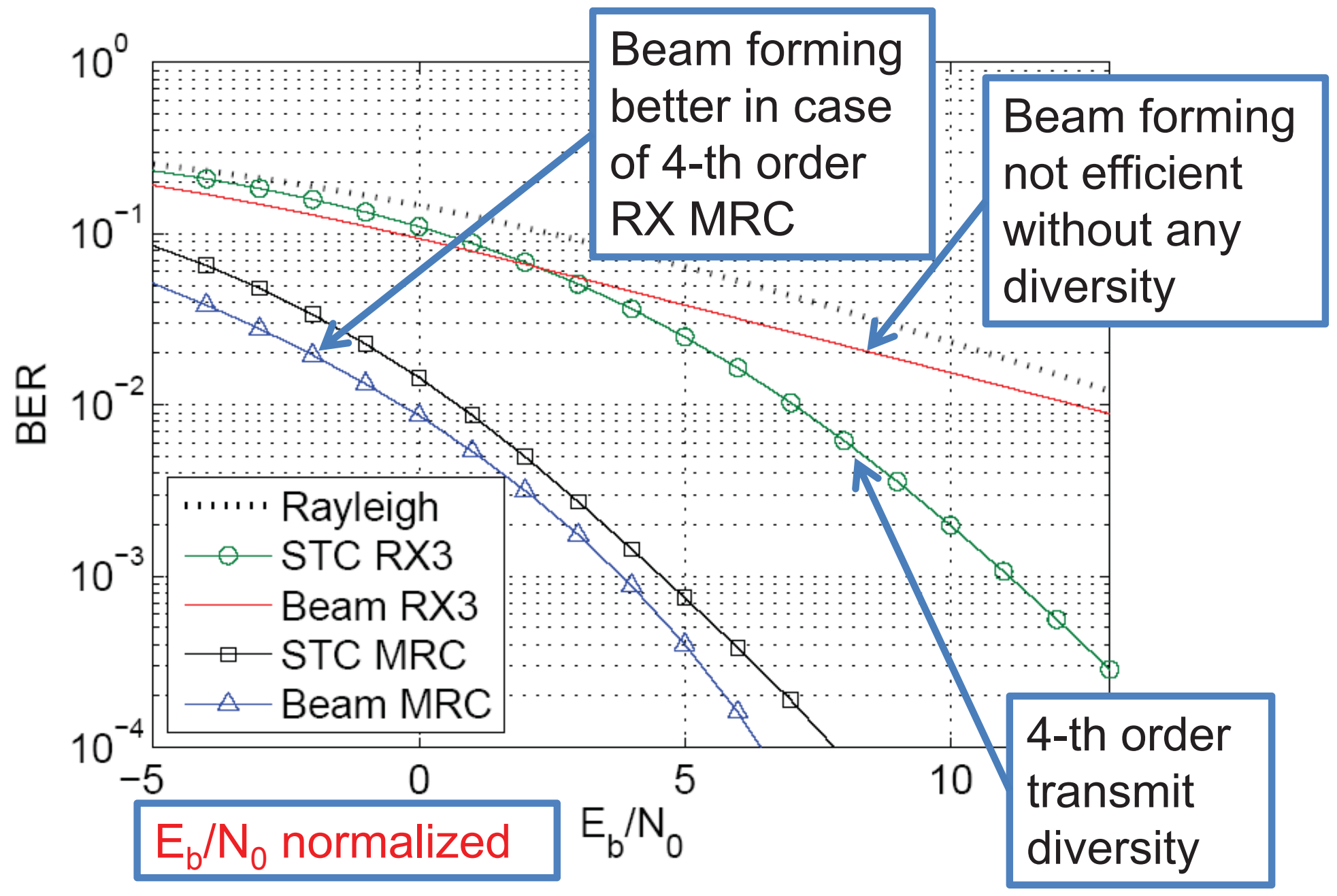

( $T X$ array gain included: equal total transmitted energy per information bit $E_{b, t r}$ ) SPT: space-time coding MRC: maximum-ratio combining 


\section{Outline}

- Wearable textile systems

- Reliability concerns

- Energy-efficiency concerns

- MIMO techniques for off-body communication

- Reliability versus energy-efficiency

- Space-time coding versus beam forming

- Integrating energy harvesters on textile antennas

- Wearable Solar-cell PIFA antenna

- Robust wearable antennas for GPS/Galileo positioning

- Providing stable performance in adverse conditions

- On-body wearable repeater as relay for implants

- In-to-out body communication in an endoscopy application

- General conclusions 


\section{Integration of energy harvesters}

\section{Wearable solar patch antenna}

- Antenna specifications

- $\left|\mathrm{S}_{11}\right|<-10 \mathrm{~dB}, 902 \mathrm{MHz}-928 \mathrm{MHz}$

- Low profile

- antenna thickness vs. bandwidth performance

- No soldered RF connections

- Robust operation in proximity human body

- Minimize bulk power absorption

- Compatible with solar cells

- Small antenna vs. solar cell area

- Based on flexible and breathable materials

Aperture-coupled shorted patch antenna 


\section{Wearable solar patch antenna}

- Antenna topology

- Shorted patch $(\lambda / 4)$

- Available area for solar cells $\left(W^{*} L\right)$

- Easy RF, DC connections

- Meandered feed line

- Aperture: H-slot

- Maximize feed coupling

- Active circuitry located beneath ground plane

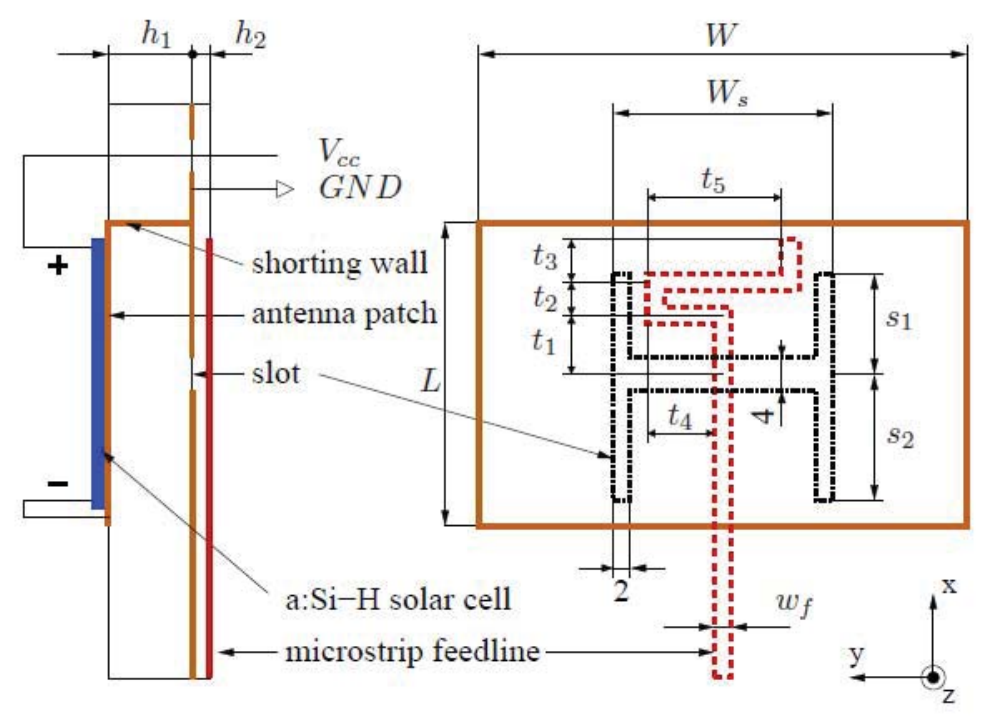

- Minimize parasitic coupling 


\section{Wearable solar patch antenna}

- Antenna materials

- Antenna substrate:

- Protective polyurethane foam

- $\mathrm{h}_{1}=10 \mathrm{~mm}$

- $\varepsilon_{\mathrm{r}}=1.16$, tan $\delta=0.010$

- Feed substrate

- 2 layers of textile aramid

- $\mathrm{h}_{2}=0.95 \mathrm{~mm}$

- $\varepsilon_{\mathrm{r}}=1.97, \tan \delta=0.020$

- Ground plane, shorting wall and patch

- Flectron: copper-coated nylon

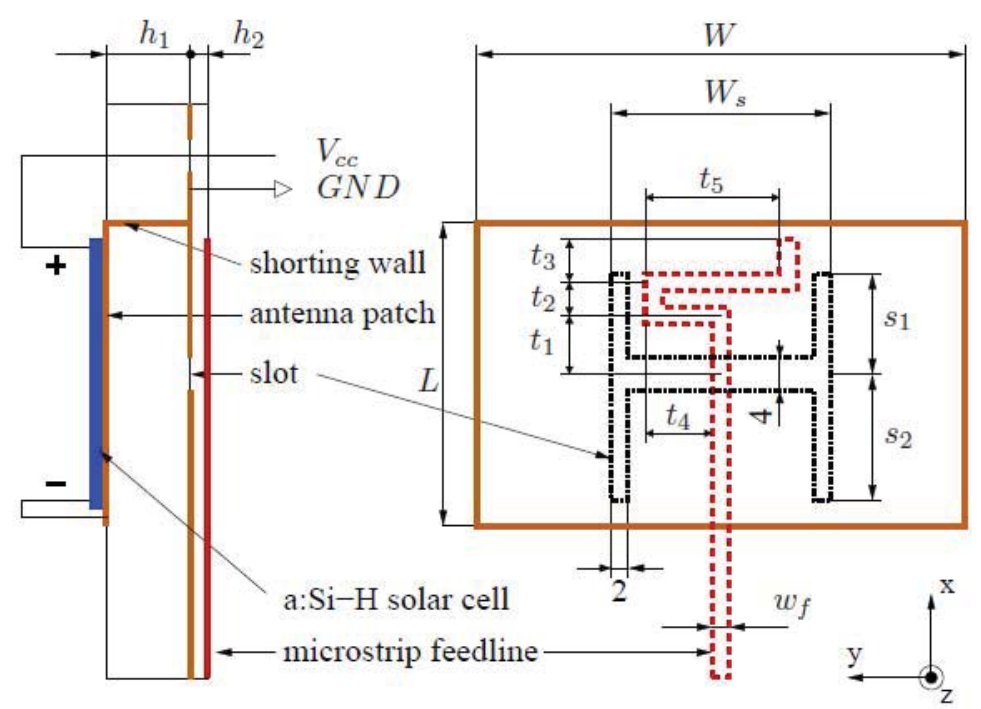
fabric

- $R_{\mathrm{s}}=0.1 \Omega / \mathrm{sq}$

- Feed line = copper foil 


\section{Wearable solar patch antenna}

- Solar cell integration

- parallel connection

- Active solar-cell area $=50 \mathrm{~mm}$ x $37 \mathrm{~mm}$ per solar cell

Wires connecting solar cells with power management module

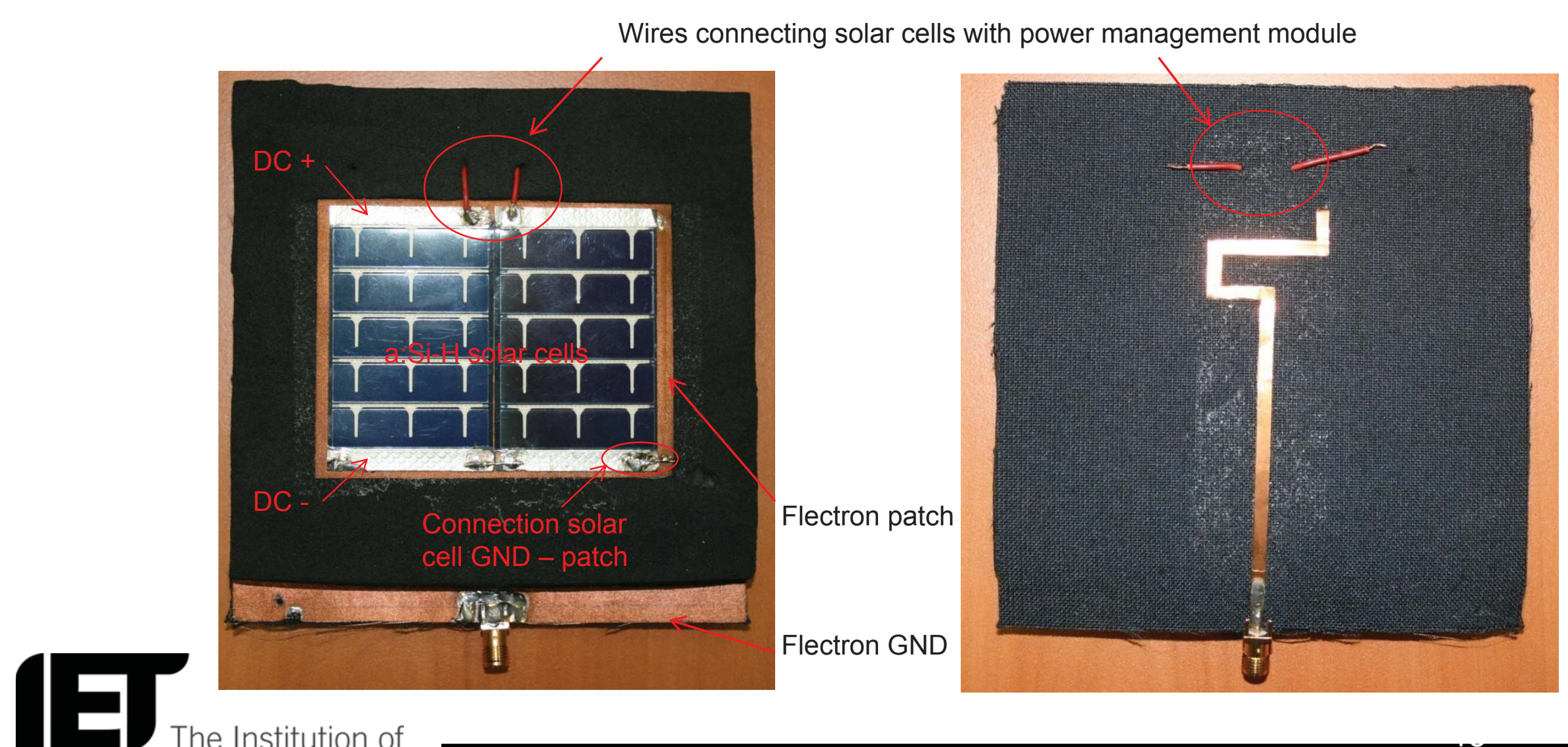




\section{Effect solar cells on antenna radiation}

- Impedance bandwidth: 48MHz@915MHz ISM band

- Free-space gain results

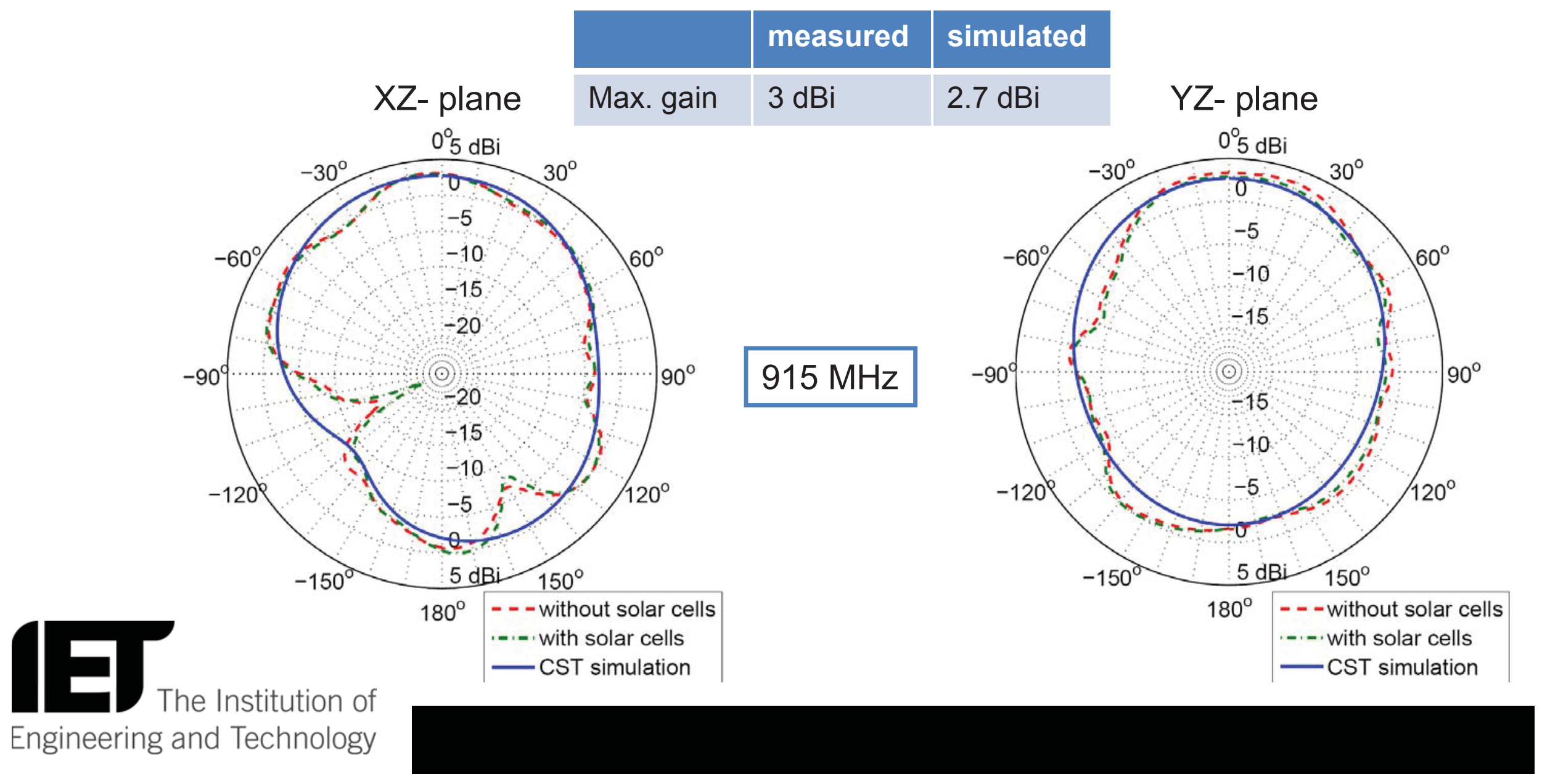




\section{Outline}

- Wearable textile systems

- Reliability concerns

- Energy-efficiency concerns

- MIMO techniques for off-body communication

- Reliability versus energy-efficiency

- Space-time coding versus beam forming

- Integrating energy harvesters on textile antennas

- Wearable Solar-cell PIFA antenna

- Robust wearable antennas for GPS/Galileo positioning

- Providing stable performance in adverse conditions

- On-Body Wearable Repeater as Relay for implants

- In-to-out body communication in an endoscopy application

- General conclusions 


\section{Wearable GNSS/Iridium antenna}

- Broadband active antenna in terms of impedance and axial ratio matching
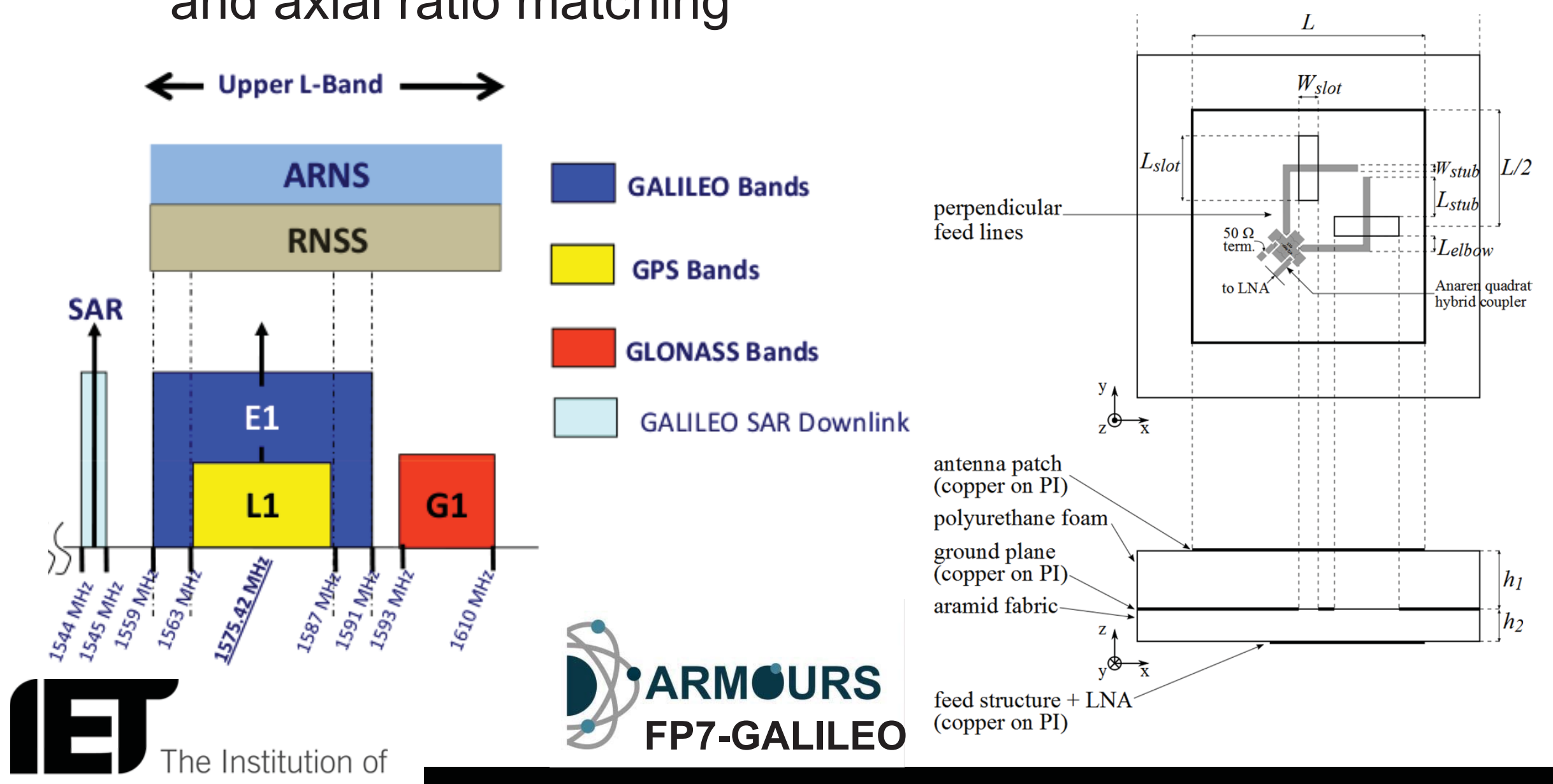


\section{Wearable GNSS/Iridium antenna}

- Broadband active antenna in terms of impedance and axial ratio matching

- antenna substrate

- polyurethane foam

- feed substrate

- aramid fabric

- dual feed with hybrid coupler Anaren XC1400P

- provides robust matching and wideband circular polarization

- active receive antenna

- Maxim MAX2659 chip LNA

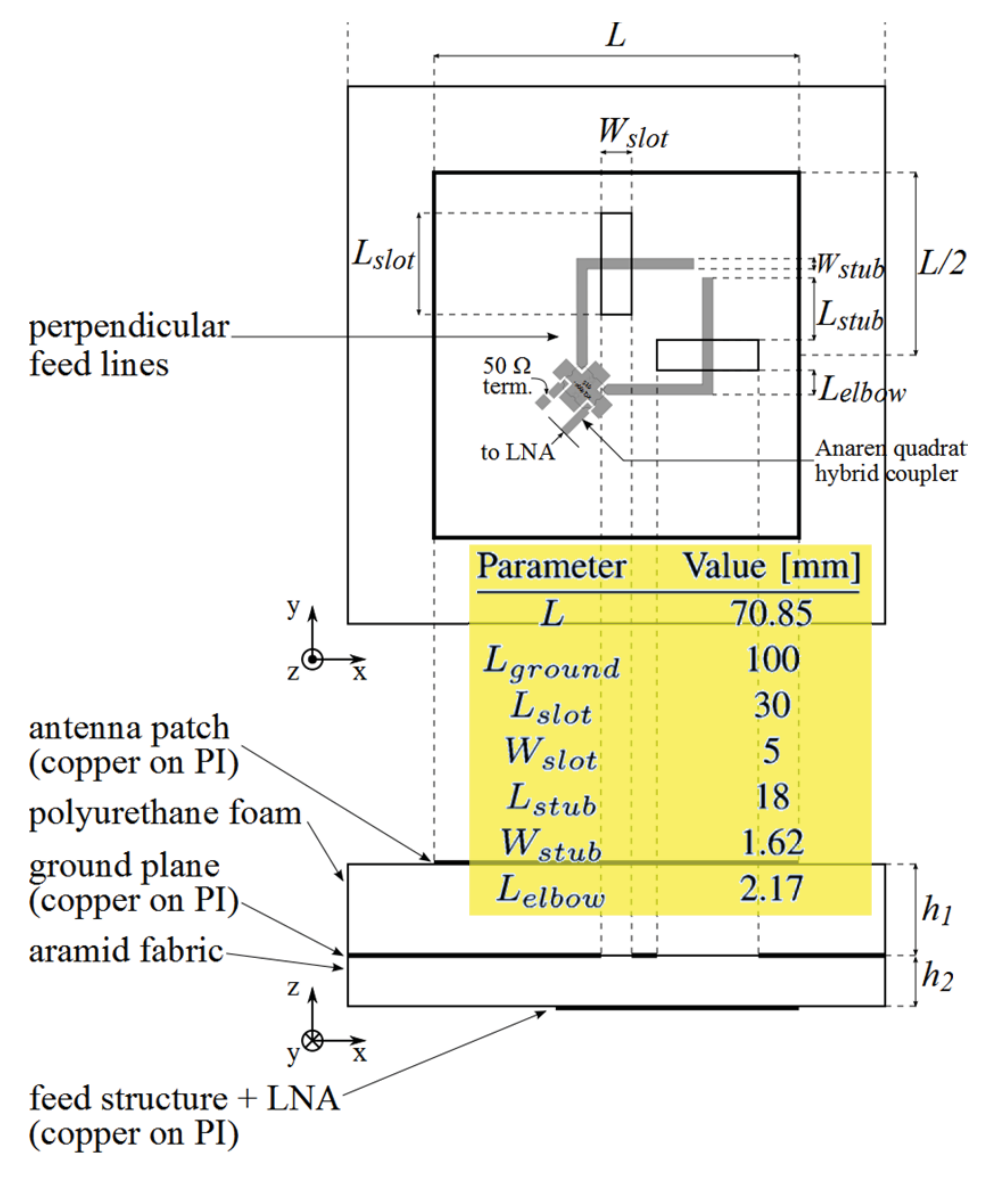

Wearable antennas for communication and localisation 


\section{Wearable GNSS/Iridium antenna}

- Passive antenna: impedance matching

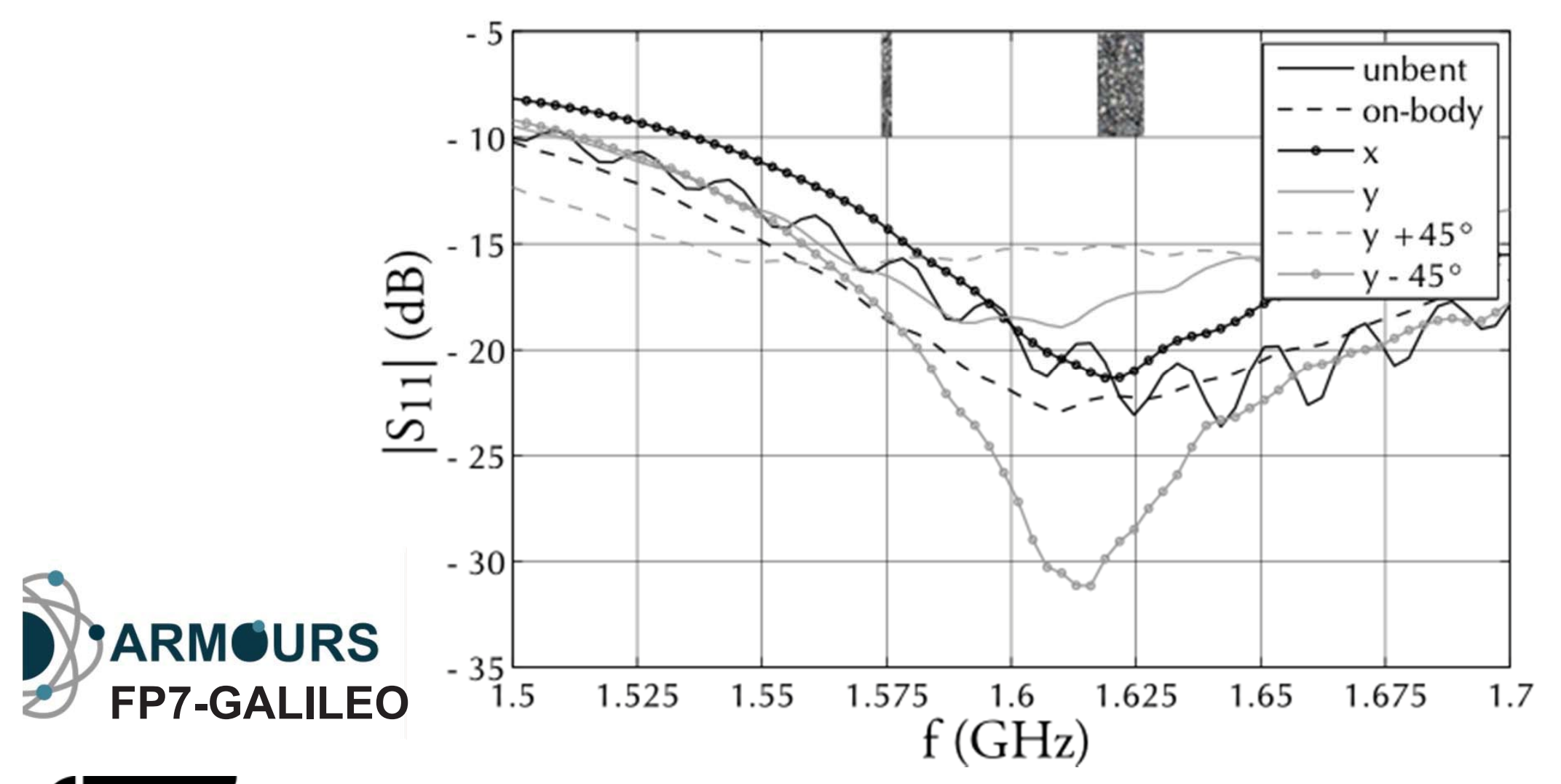




\section{Wearable GNSS/Iridium antenna}

- Passive antenna: Gain

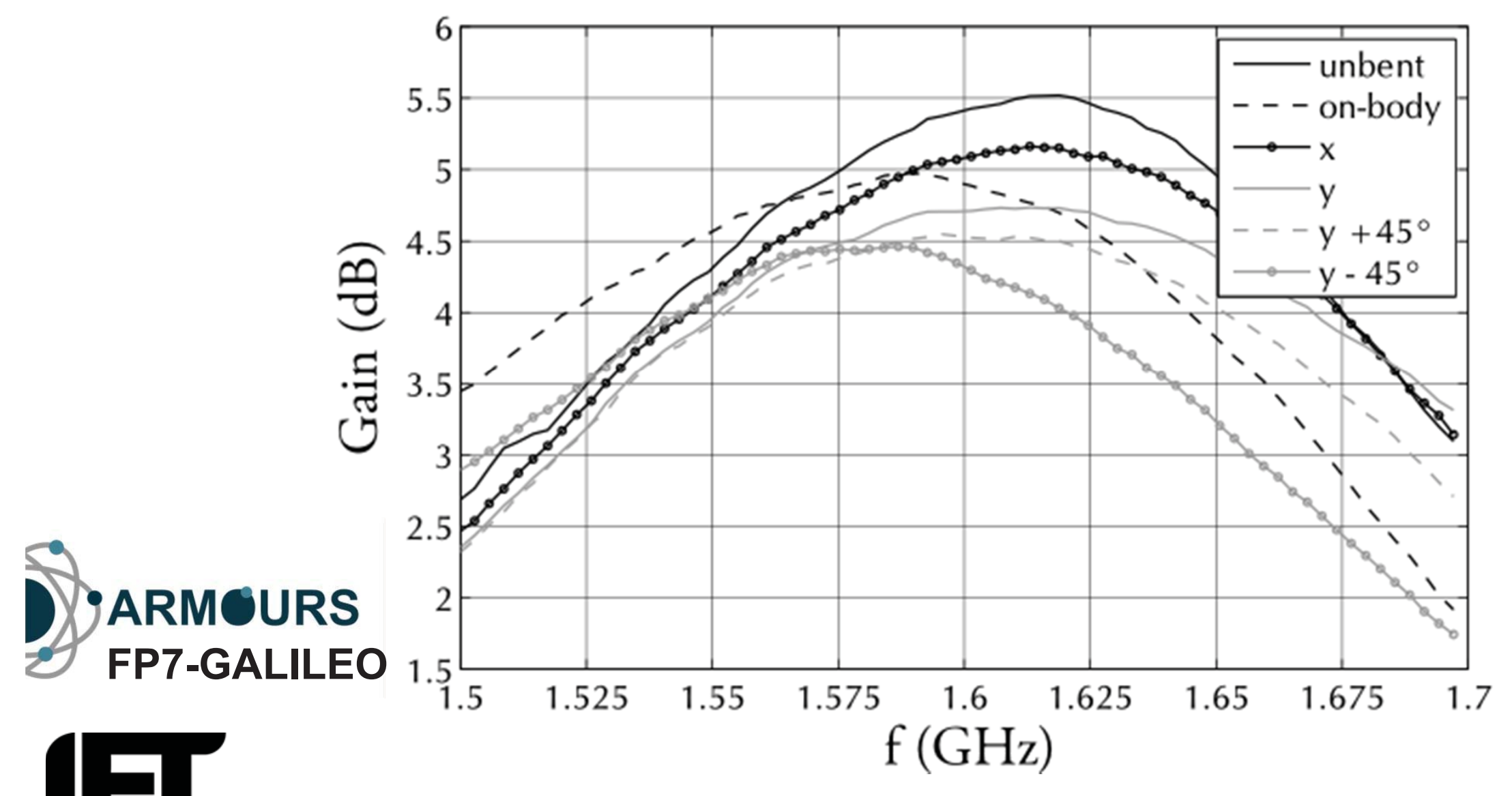




\section{Wearable GNSS/Iridium antenna}

- Passive antenna: Axial Gain

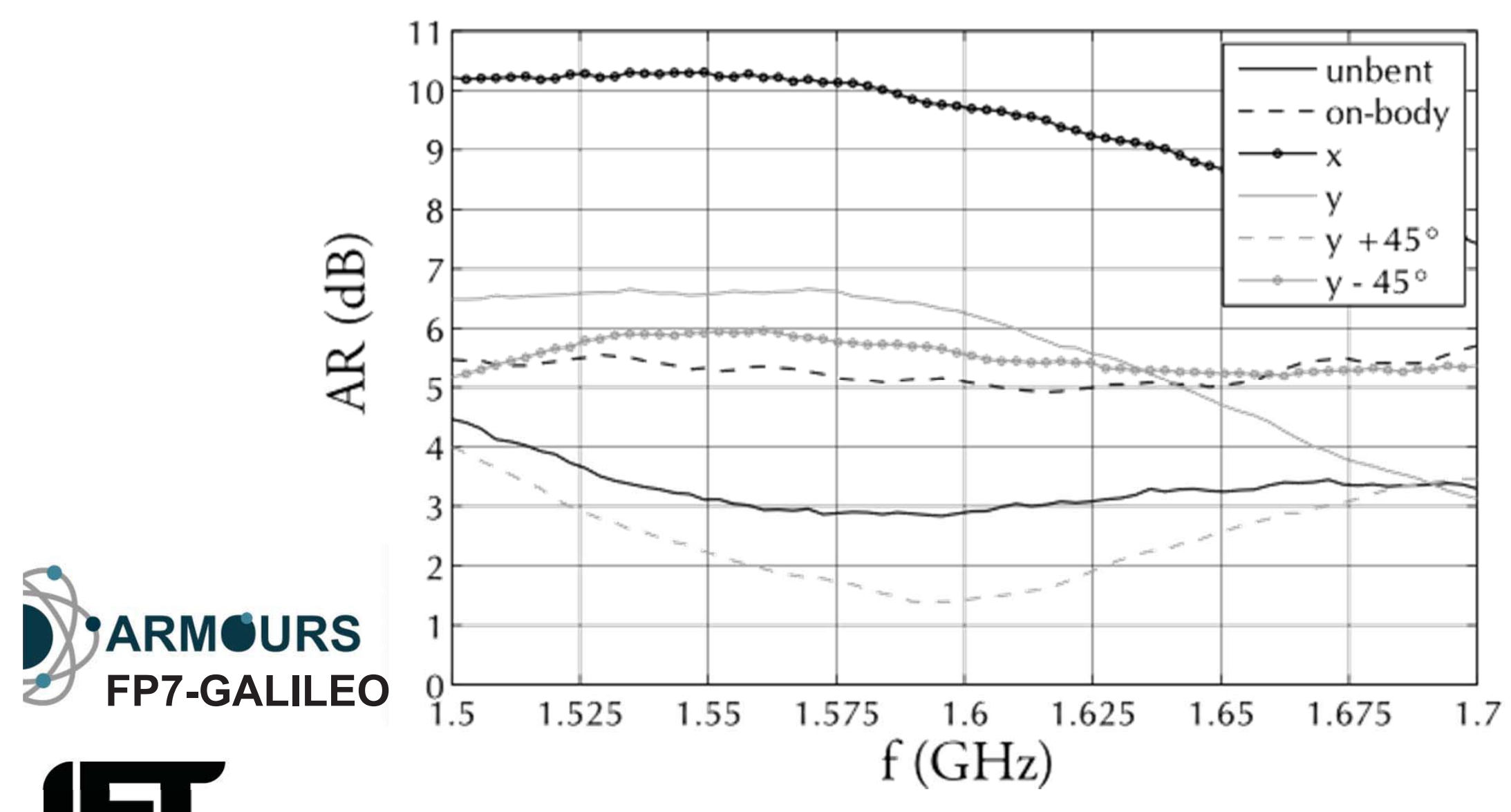




\section{Wearable GNSS/Iridium antenna}

- Main figures of merit

\begin{tabular}{|l|l|l|}
\hline & Passive antenna & Active antenna \\
\hline Gain $(\mathrm{dBi})$ & 5.2 & 25.1 \\
\hline 3 dB beam width & $66^{\circ}$ & $68^{\circ}$ \\
\hline $\begin{array}{l}\text { Axial ratio }(\mathrm{dB}) \\
\text { 3 dB axial ratio beam width }\end{array}$ & 2.476 & 1.866 \\
\hline $\begin{array}{l}\text { Matching bandwidth (free- } \\
\text { space) }\end{array}$ & $\begin{array}{l}288 \mathrm{MHz}(1.512 \mathrm{GHz}-1.8 \\
\mathrm{GHz})\end{array}$ & $\begin{array}{l}3406^{\circ} \\
\mathrm{GHz})\end{array}$ \\
\hline $\begin{array}{l}\text { Axial ratio bandwidth (free- } \\
\text { space) }\end{array}$ & $\begin{array}{l}52 \mathrm{MHz}(1.558 \mathrm{GHz}-1.61 \\
\mathrm{GHz})\end{array}$ & $\begin{array}{l}183 \mathrm{MHz}(1.517 \mathrm{GHz}-1.7 \\
\mathrm{GHz})\end{array}$ \\
\hline
\end{tabular}




\section{Outline}

- Wearable textile systems

- Reliability concerns

- Energy-efficiency concerns

- MIMO techniques for off-body communication

- Reliability versus energy-efficiency

- Space-time coding versus beam forming

- Integrating energy harvesters on textile antennas

- Wearable Solar-cell PIFA antenna

- Robust wearable antennas for GPS/Galileo positioning

- Providing stable performance in adverse conditions

- On-body wearable repeater as relay for implants

- In-to-out body communication in an endoscopy application

- General conclusions 


\section{On-body wearable repeater antenna}

- Wearable repeater antenna

- Relay: endoscopy capsule (implanted dipole) 企

remote base station (RX)

1. textile receive antenna $\left(R X_{\text {rep }}\right)$ matched to body

2. amplifier

3. textile transmit antenna $\left(\mathrm{TX}_{\text {rep }}\right)$ matched to free space 


\section{Repeater textile receive antenna}

- Robustly matched to body

- Foam substrate

- Electrotextile

- Ground plane

- Antenna plane

- Foam spacer

- stabilizes bandwidth when deploying antenna on different body parts

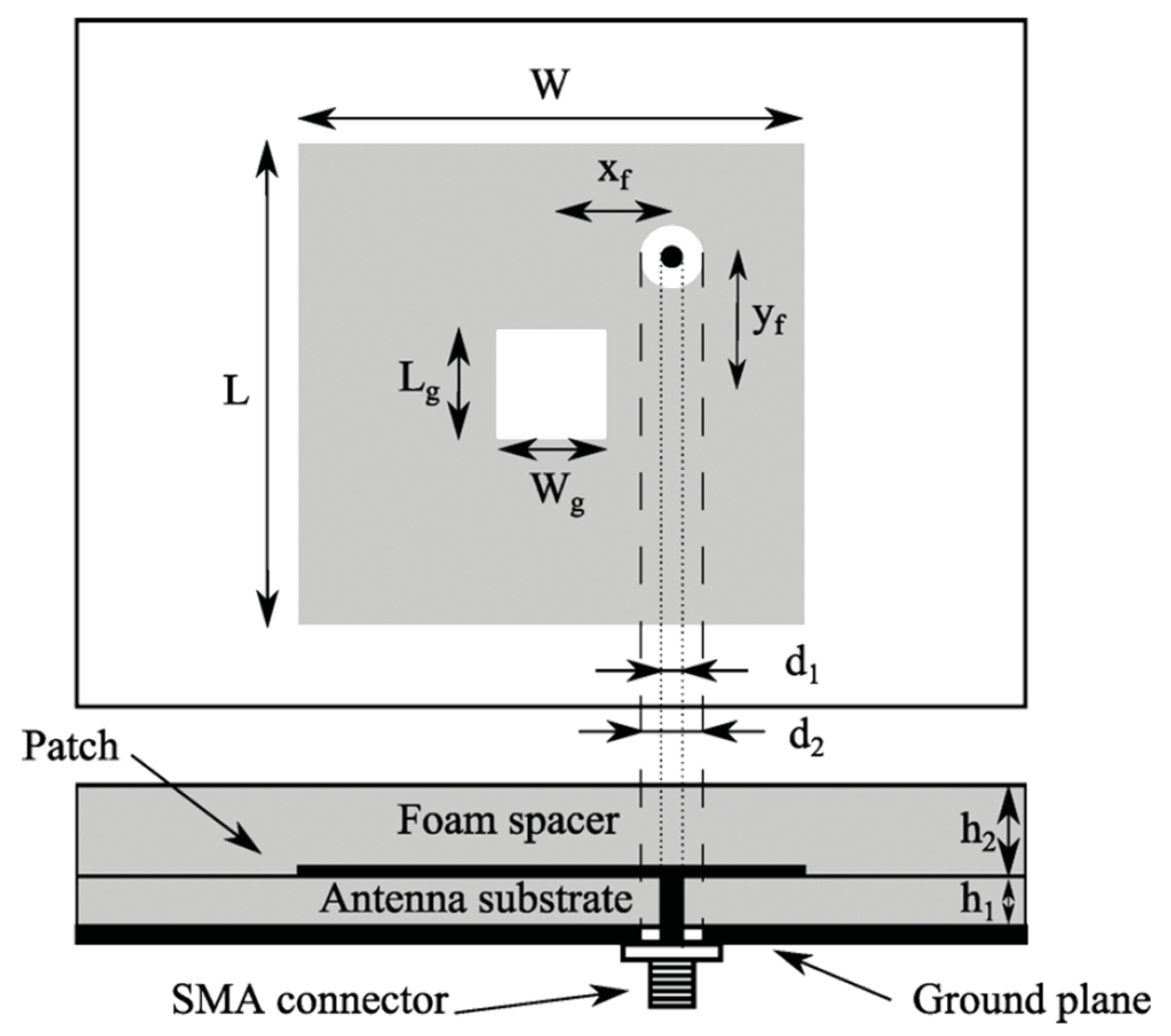




\section{Repeater textile receive antenna}

- Reflection coefficient when deploying antenna on different body locations
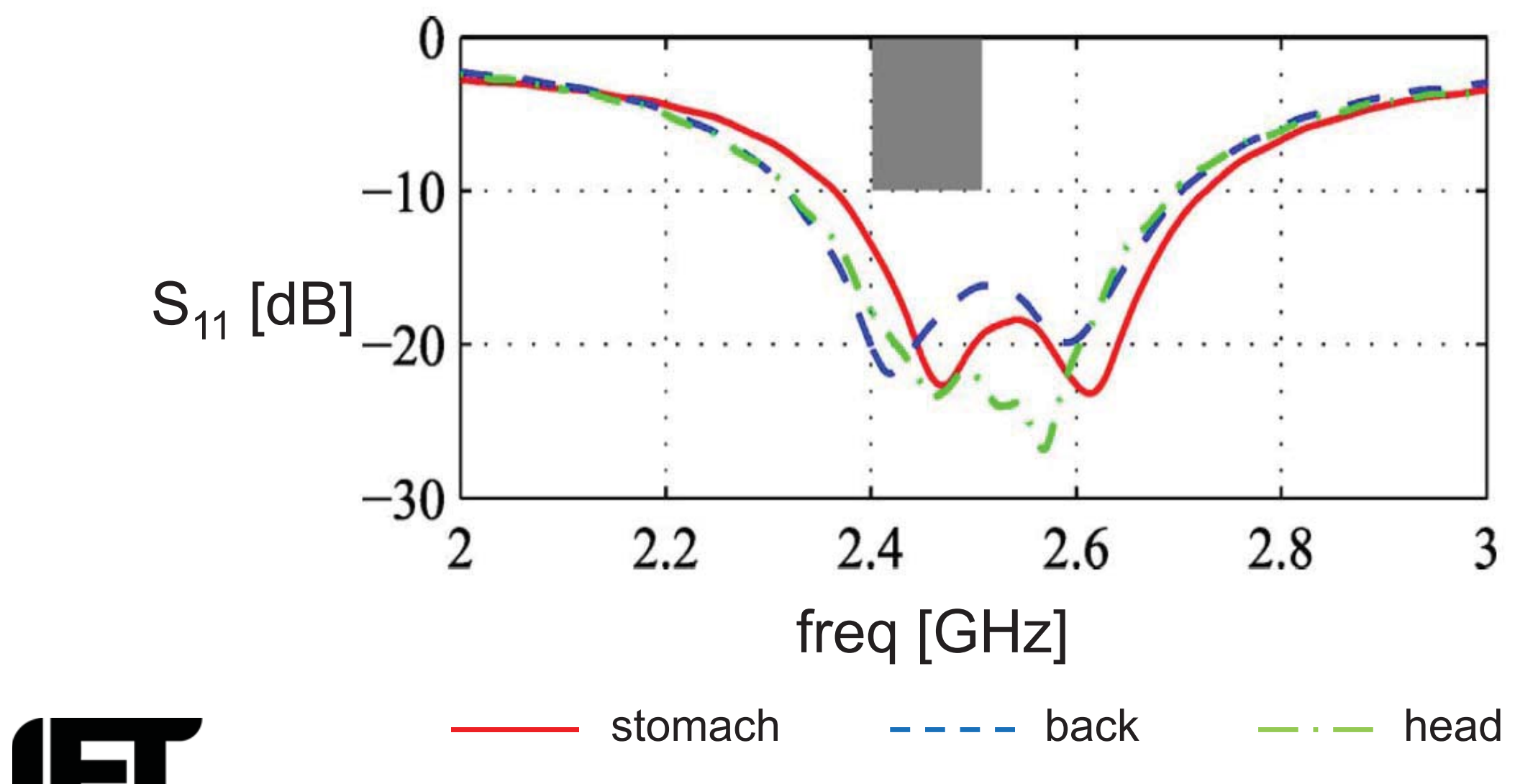


\section{On-body wearable repeater antenna}

- implant transmit power $10 \mathrm{~mW}$, 2Mb/s QPSK test transmission

- average SNR at RX, without repeater: $8 \mathrm{dBi}$

- average SNR at repeater: $30.1 \mathrm{~dB}$

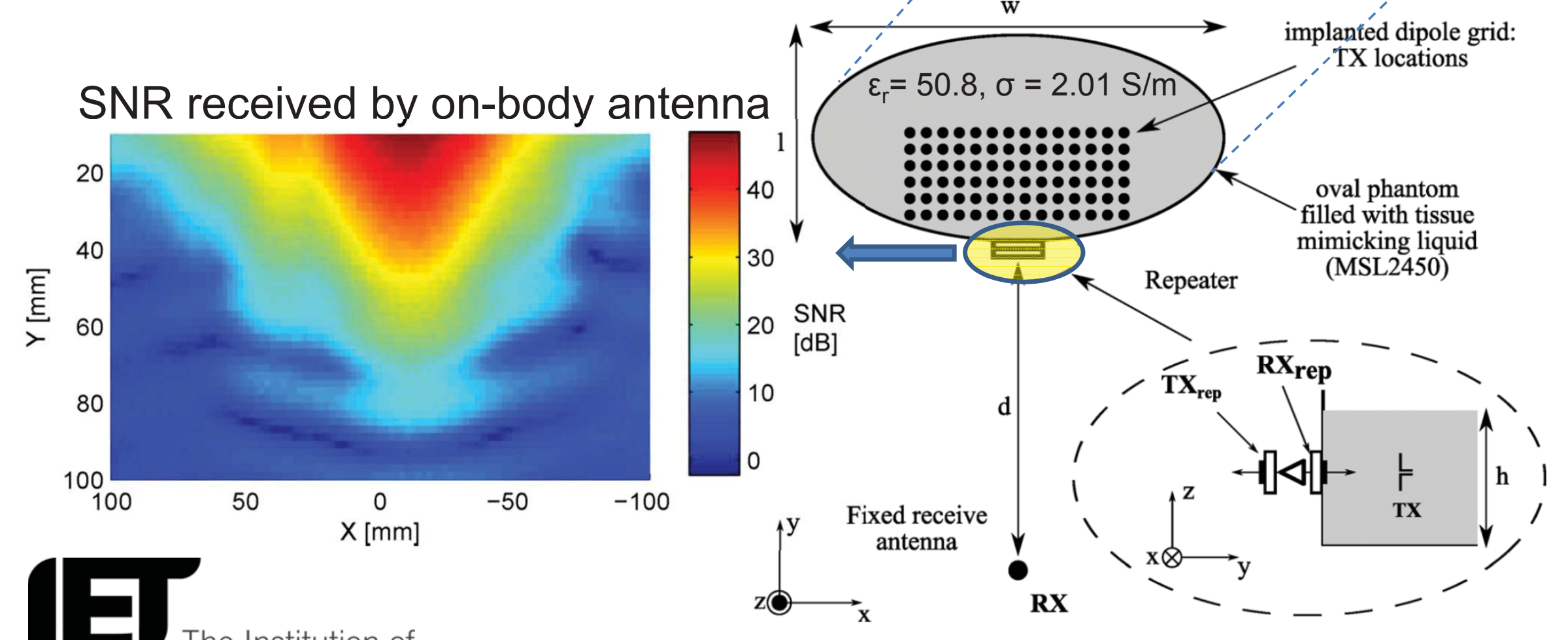




\section{On-body wearable repeater antenna}

- implant transmit power $10 \mathrm{~mW}$

- Repeater with analog amplifier $4.38 \mathrm{~dB}$ gain

- average SNR at RX: $33 \mathrm{~dB}$

SNR received at $R X$

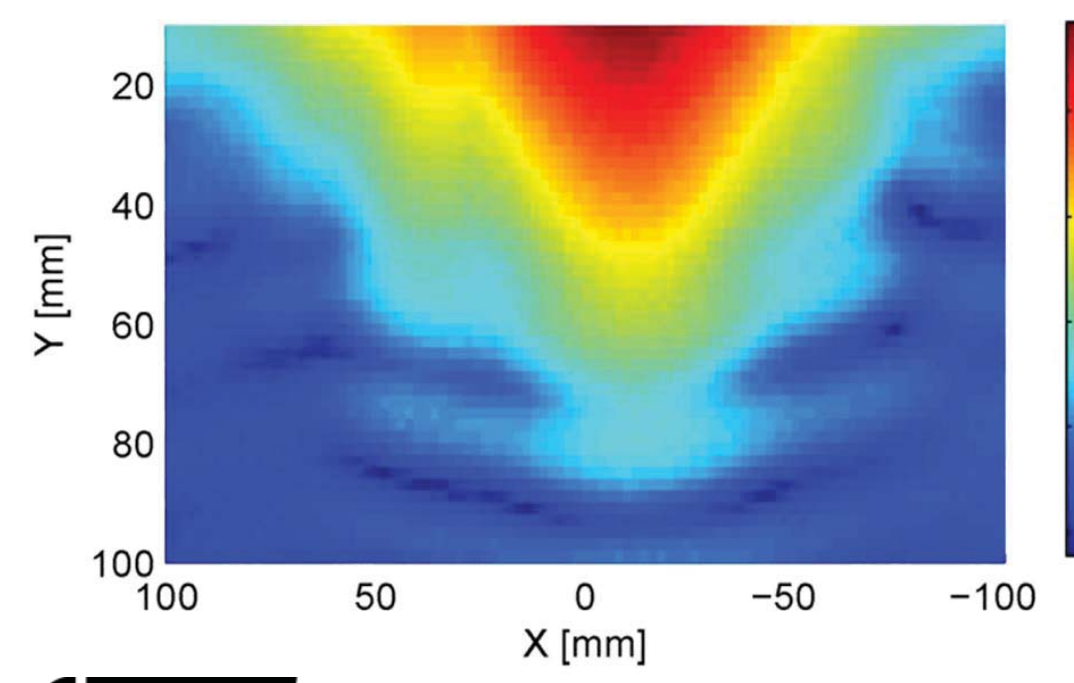




\section{General conclusions}

- Challenges for reliable body-centric communications

- Mechanical robustness

- Avoid fragile links such as vias

- Build compact active antenna modules

- Stable antenna performance

- Account for adverse effects during design

- Test prototypes in realistic conditions

- Mitigating fading/shadowing in the propagation channel

- Make use of body as a large platform to deploy a multi-antenna system

- Use space-time codes for transmit/receive diversity 